\title{
Evitar la visió precària de la comunicació alimentària. Una necessitat estratègica
}

\author{
Manuel Murillo Rosado \\ Facultat de Filologia i Comunicació, Universitat de Barcelona \\ manuelmurillorosado@ub.edu
}

Recepció: 27/04/2021, acceptació: 21/07/2021

Resum: Avui dia la comunicació alimentària que transcendeix als mitjans de comunicació, internet i les xarxes socials està protagonitzada, majoritàriament, per la informació relativa a les alertes alimentàries. No obstant això, una anàlisi exhaustiva $i$ àmplia de la comunicació alimentària evidencia camps de treball més enllà del sanitari, com les noves tecnologies dels aliments, la nutrigenòmica o aspectes erròniament no identificats amb la comunicació alimentària, com l'accessibilitat als aliments o els sistemes de producció alimentària sostenibles i protecció davant el canvi climàtic, entre d'altres. És necessària una revisió de l'àmbit d'estudi de la comunicació alimentària i situar-la en un espai estratègic que des d'inicis del segle xx ja s'anava intuint i que avui dia encara no és contemplat, malgrat ser protagonista en temes tan innovadors i decisius per al progrés de la societat i el planeta.

Paraules clau: comunicació alimentària, seguretat alimentària, alerta sanitària, indústria alimentària, seguretat nutricional.

Evitar la visión precaria de la comunicación alimentaria. Una necesidad estratégica.

Resumen: Hoy en día la comunicación alimentaria que trasciende a los medios de comunicación, internet y las redes sociales está protagonizada, en su mayoría, por la información relativa a las alertas alimentarias. Sin embargo, un análisis exhaustivo y amplio de la comunicación alimentaria evidencia campos de trabajo más allá del sanitario, como las nuevas tecnologías de los alimentos, la nutrigenómica o aspectos erróneamente no identificados con la comunicación alimentaria, como la accesibilidad a los alimentos o los sistemas de producción alimentaria sostenibles y protección ante el cambio climático, entre otros. Es necesaria una revisión del ámbito de estudio de la comunicación alimentaria y situarla en un espacio estratégico que desde inicios del siglo xx ya se intuía y que hoy en día aún no es contemplado, pese a ser protagonista en temas tan innovadores y decisivos para el progreso de la sociedad y el planeta.

Palabras clave: comunicación alimentaria, seguridad alimentaria, alerta sanitaria, industria alimentaria, seguridad nutricional.

\section{Avoiding tunnel vision in food communication: A strategic need}


Abstract: Today, food communication that transcends the media, the Internet and social networks is mostly driven by information regarding food alerts. However, a thorough and comprehensive analysis of food communication must consider fields beyond those that are health-related, such as new food technologies or nutrigenomics, as well as other fields that have so far erroneously not been identified with food communication, such as accessibility to food or food systems, sustainable food production and protection from climate change, among others. It is necessary to review the field of study on food communication and place it in a strategic space that was already hinted at at the beginning of the 2oth century but that has not yet been properly considered, in spite of the field's protagonism in innovative topics that are decisive for the progress of society and the planet alike.

Keywords: food communication, food safety, health alerts, food industry, food security.

\section{L'ÀMBIT DE CONEIXEMENT DE LA COMUNICACIÓ ALIMENTÀRIA}

En la comunicació alimentària els temes relatius a la seguretat i la innocuïtat dels aliments són de gran interès per als mitjans de comunicació. Aquests s'erigeixen en transmissors dels riscos del consum de determinats productes que són al mercat $\mathrm{i}$, per tant, que poden trobar-se a l'abast de tots els consumidors. No obstant això, parlar de «comunicació dels aliments» té diversos vessants, més enllà de ser una part important $\mathrm{i}$ necessària en la gestió de les alertes alimentàries.

En aquest sentit, la comunicació alimentària o dels aliments podria subdividir-se en diversos espais informatius en els mitjans de comunicació, internet i les xarxes socials, segons l'enfocament de la informació, com els següents:

- Seguretat alimentària (relativa a la informació sobre alertes alimentàries, riscos per a la salut, prevenció i gestió de crisis alimentàries i etiquetatge dels productes);

- Educació, divulgació nutricional i hàbits de consum saludables (campanyes sobre alimentació i rutines de consum i les bondats que determinats aliments tenen sobre la salut i el benestar personal i col-lectiu);

- Innovació sobre tecnologia dels aliments (informació sobre avanços agroalimentaris, disseny i $\mathrm{R}+\mathrm{D}+\mathrm{I}$ de «nous aliments» $\mathrm{i}$ «aliments frontera», com els probiòtics o prebiòtics, entre d'altres);

- Alimentació sostenible (agricultura, ramaderia i aliments que afavoreixen la sostenibilitat del planeta des del punt de vista mediambiental i de lluita contra la fam en la societat d'acord amb els Objectius del Mil-lenni de l'ONU);

- Indústria alimentària com a sector econòmic i generador d'ocupació (informació sobre empreses, corporacions, el sector agroalimentari i el seu pes en el producte interior brut i l'actualitat corporativa nacional i internacional).

Podria afegir-s'hi també el màrqueting i la comunicació de la indústria agroalimentària, ramadera i pesquera des d'un punt de vista corporatiu i organitzacional, però no és el cas d'estudi en aquest article.

És curiós comprovar les diferents interpretacions del terme «seguretat alimentària» que es fan depenent de la procedència del mitjà de comunicació. Fonamentalment, si es tracta d'un mitjà iberoamericà, té l'accepció de 'subalimentació'. En canvi, en els mitjans catalans i espanyols, s'identifica amb 'les característiques innòcues per a la salut del consum d'un determinat producte alimentari'. Així mateix, l'Organització de les Nacions 
Unides per a l'Alimentació i l'Agricultura (FAO) assenyala com a característiques de la «seguretat alimentària i nutricional» el fet de tenir menjar disponible, que hi hagi una manera d'aconseguir-lo (per exemple, diners per comprar aliments), que aquests aliments siguin suficients, innocus i nutritius perquè el nostre cos pugui aconseguir l'energia i els nutrients necessaris per tenir una vida sana, i, finalment, que aquesta situació sigui continuada en el temps.

En part, aquesta confusió i ambivalència en la interpretació del terme «seguretat alimentària» podria ser conseqüència, principalment, d'una deficient traducció de food security (que fa referència en anglès a l'accés als aliments) i food safety (que s'identifica amb la innocuïtat dels aliments). Els mitjans de comunicació gairebé no consideren les informacions sobre food security com a informacions relatives a la comunicació alimentària, sinó que més aviat es relaciona amb el Tercer Sector i la solidaritat.

Avui dia també cal tenir en compte nous camps disruptius de la comunicació alimentària que estan adquirint importància i que tenen a veure fonamentalment amb la recerca genètica (nutrigenòmica o la informació sobre la microbiota intestinal, entre d'altres). També trobem la recerca que la indústria farmacèutica i els centres de referència estan fent sobre els productes i aliments de la mar i les seves particularitats. Fins i tot, nous àmbits com la bioinformàtica s'estan enfocant molt en aquest moment en el tractament de grans volums de dades. Tant és així que l'objectiu és cercar respostes en les big-data i la intel-ligència artificial en dos àmbits principals: la salut i el sector alimentari (Bioinformàtics Barcelona 2015).

La comunicació alimentària és, consegüentment, molt polièdrica i multidisciplinària, ja que, amb el denominador comú de l'aliment, la informació transita en diferents seccions dels mitjans de comunicació (societat-salut, economia-empresa, innovació, educació i, fins i tot, gastronomia, nutrició i estètica i bellesa).

Podríem definir d'aquesta manera un àmbit ampli de «comunicació alimentària o dels aliments»? És complicat, ja que la comunicació alimentària sembla només patrimoni de la comunicació de crisi, és a dir, de la comunicació relativa a la gestió de les crisis sanitàries provocades per les alertes pel consum d'aliments en mal estat i les seves conseqüències en la població. $\mathrm{Ni}$ els mitjans de comunicació, ni els periodistes, ni la formació de comunicadors i divulgadors aglutinen i dominen tot el coneixement i la influència que l'univers informatiu dels aliments té en aquest moment i tindrà en un futur pròxim. Per això s'ha optat per l'opció precària i no àmplia de la comunicació alimentària.

El filòsof i antropòleg alemany Ludwig Feuerbach va dir, el 1850, en el seu escrit Ensenyament de l'alimentació (Lehre der Nahrungsmittel: Für dónes Volk): «Si es vol millorar el poble, en comptes de discursos contra els pecats, donin-li millors aliments. L'home és el que menja», que amb el temps sovint s'ha interpretat com «som el que mengem» (Los Infoodistas 2021). Sens dubte, va esdevenir una de les primeres accions divulgatives sobre la comunicació dels aliments que va tenir poc a veure amb la innocuïtat dels aliments, sinó més aviat amb el dret a l'accés als aliments per part de la població més desfavorida. No obstant això, anys més tard, el 1906, la societat americana es va alarmar sobre, en aquest cas, la salubritat i innocuïtat dels aliments a conseqüència de la publicació de la novel-la La Jungla (Collado Santiago 2013), del periodista i novel-lista estatunidenc Upton Sinclair. S'hi descrivien les dures condicions de vida i d'explotació en un escorxador de Chicago d'immigrants nouvinguts als Estats Units a la recerca del «somni americà». Sinclair il.lustrava les deficients i escandaloses condicions d'insalubritat d'aquestes instal-lacions, i l'insà tractament que la indústria càrnia de llavors donava als seus productes, fet que va escandalitzar la societat estatunidenca de principis del segle $\mathrm{xx}$. 
Aquesta indefinició conceptual, i el poc clar abast de la comunicació alimentària, també pot veure's reflectida en l'oferta formativa sobre seguretat alimentària i comunicació alimentària que existeix en els plans docents universitaris. D’aquesta manera, en màsters oficials com l'interuniversitari de Seguretat Alimentària de la Universitat de Barcelona i la Universitat Autònoma de Barcelona (Universitat de Barcelona 2021), la comunicació fa referència fonamentalment a la «comunicació de crisi». D’altra banda, màsters com el Màster Universitari en Nutrició Humana i Dietètica Aplicada de la Universitat Complutense de Madrid (Universidad Complutense de Madrid 2021) o cursos especialitzats com el d'Especialitat en Educació i Comunicació Alimentària de la Universitat Oberta de Catalunya (Universitat Oberta de Catalunya 2021) s'enfoquen més en aspectes de comunicació nutricional, d'hàbits de consum i, fins i tot, imatge personal.

\section{Societat i CRedibilitat del Periodista Alimentari}

El número 1 de la revista Alimentació i comunicació (setembre 2020), editada per l'Observatori de la Comunicació Científica (OCC-UPF) de la Universitat Pompeu i Fabra i el Departament d'Agricultura, Ramaderia, Pesca i Alimentació de la Generalitat de Catalunya, reflectia una enquesta sobre els principals temes d'interès de la societat catalana en matèria d'alimentació. En l'article "Quins són els interessos i hàbits informatius de la població relacionats amb l'alimentació?» (Casino 2017) d'aquest monogràfic, escrit per Gonzalo Casino, director adjunt de l'OCC-UPF, s'afirma que «l'interès de la població catalana pels temes alimentaris divulgats a través dels mitjans de comunicació, internet i les xarxes socials és entre mitjà i alt (3,47 sobre 5)». Afegeix que «els tres temes alimentaris que més inquieten la població de Catalunya són els efectes que tenen els aliments en la salut, les idees i notícies falses sobre alimentació i l'impacte de la producció dels aliments sobre el medi ambient». Aquests tres assumptes destacats són els únics que susciten «bastant interès» (4 sobre 5). En l'article Casino també afirma que «la població és molt receptiva a rebre informació i aprendre sobre els temes d'alimentació, però troba a faltar fonts de confiança. Es detecta que existeix un espai i una necessitat de nous canals que ofereixin o filtrin informació de qualitat». El més sorprenent d'aquesta enquesta, realitzada mitjançant un grup focal, és que els metges i altres sanitaris, juntament amb els científics, són els professionals que mereixen major credibilitat quan s'informen sobre alimentació. D’altra banda, però, els periodistes i els tècnics de l'Administració són els professionals que mereixen menor credibilitat quan informen sobre aquests temes.

Segons les dades de la Agencia Española de Seguridad Alimentaria y Nutrición (AESAN) (Ministerio de Consumo 2021), durant el 2020 es van notificar 356 alertes alimentàries a Espanya, que inclouen informació sobre «aquelles alertes alimentàries que hagin de ser objecte d'informació pública, tant per la seva repercussió sanitària com per la seva possible distribució al consumidor final. No s'inclouen les alertes alimentàries d'al-lergògens ni les de complements alimentaris que, per les seves característiques particulars, disposen d'una subsecció específica». Aquestes alertes alimentàries, juntament amb la informació que proporcionen les principals associacions de consumidors i les entitats administratives de seguretat alimentària autonòmiques (recollides principalment per les agències d'informació general com EFE [EFE Agro], Europa Press i l'Agència Catalana de Notícies [ACN] en els seus despatxos) són les principals fonts d'informació dels mitjans de comunicació. Tanmateix, segons Juan Ramón Hidalgo, advocat especialitzat en seguretat alimentària, professor del màster de Seguretat Alimentària de la UB i expresident de la Sociedad Española de Seguridad 
Alimentaria, en poques ocasions les Pimes que sofreixen una crisi alimentària gestionen convenientment la comunicació.

Segons dades de la Promotora dels Aliments Catalans (PRODECA 2021), el sector agroalimentari genera un volum de negoci de $38.205 \mathrm{M€}$, xifra que equival al 16,28\% del PIB de Catalunya, i que proporciona una ocupació directa a 163.372 persones. Aquestes dades el converteixen en el primer sector econòmic del país. L’integren 57.423 explotacions agràries, 3.922 indústries d'alimentació i begudes i 436 establiments de la indústria auxiliar agroalimentària. D'aquestes 3.922 empreses agroalimentàries catalanes, que representen un 12,5\% de les espanyoles, el $75 \%$ són Pimes que tenen menys de 10 treballadors. Aquest fet provoca que quan es produeix una crisi alimentària, que majoritàriament afecta petites i mitjanes empreses locals, els mitjans de comunicació no accedeixin a la font de primera mà. Això porta a una institucionalització de la informació, ja que el periodista es nodreix de la informació oficial dels organismes d'intervenció i control i de les agències d'informació generals. Aquesta comunicació de crisi no només afecta la claredat de la situació d'alerta alimentària, sinó també la reputació de marca de la companyia afectada, la qual cosa posa en moltes ocasions en perill la viabilitat del negoci i els seus llocs de treball.

\section{Conclusions}

- La comunicació alimentària ha estat vigent des dels inicis del segle xx en els mitjans de comunicació i en la societat, tant en el seu vessant d'innocuïtat com d'accessibilitat als aliments. Durant el segle passat la comunicació alimentària ha tingut fonamentalment una gran importància en l'àmbit de la salut, que encara perdura com un dels aspectes més significatius, però no l'únic.

- Amb la creació d'organismes d'inspecció i control, normes de seguretat i legislació sobre informació i drets dels consumidors, la informació alimentària de crisi, sobretot a causa de les alertes alimentàries, és la que major pes i rellevància té en els mitjans de comunicació (per sobre d'altres aspectes importants econòmics, ambientals, socials i tecnològics).

- Avui dia els aliments comprenen nous espais de desenvolupament, progrés, recerca i oportunitats que estan configurant una pedra angular en el futur del progrés econòmic i social de la nostra societat. La comunicació alimentària no ha de donar l'esquena a aquests nous àmbits estratègics $i$ ha d'erigir-se en protagonista de la transmissió dels seus continguts.

- El comunicador alimentari, des de la responsabilitat de recaptar informació precisa, analitzar-la i interpretar-la per a una major comprensió de la societat (tasca periodística), ha de ser el responsable del seu tractament i divulgació. Per això és necessària una adequada formació que comprengui tots els àmbits en els quals els aliments estan afectant la vida tant de les persones com del planeta, sobretot amb l'avanç de la ciència i tecnologia en sectors com la genòmica i la intel-ligència artificial, entre d'altres.

- No existeix una oferta formativa en l'actualitat que reculli tots els àmbits de la comunicació alimentària des d'un vessant transversal i multidisciplinari, tant des d'un punt de vista de continguts com estratègic, que tingui en compte el progrés de la societat i del seu entorn.

\section{RefERÈnCIEs Bibliogràfiques}

BioINFORMàtics BARCelona, BiB (2015). Se constituye la Asociación Bioinformàtics Barcelona

$B I B$.

Web: 
http://www.bioinformaticsbarcelona.eu/news/8/es-constitueix-l-associacio-bioinformati cs-barcelona-bib

CAsino, Gonzalo (2017). «¿Cuáles son los intereses y hábitos informativos de la población relacionados con la alimentación?» Revista Alimentación y Comunicación, núm. 1, OCC-UPF, págs. 04-11.

Collado Santiago, José (2013). El impacto de La Jungla de Upton Sinclair en la Sociedad Americana de la Era Progresista (190o) [Tesi de doctorat. Universitat d'Oviedo]. Repositorio Institucional de la Universidad de Oviedo

Los Infoodistas (2021). Ciudades hambrientas, un libro sobre qué comemos y cómo comemos.

Web:

https://losfoodistas.com/ciudades-hambrientas-libro-sobre-que-comemos/

Ministerio de Consumo, Agencia Española de Seguridad Alimentaria y Nutrición, AESAN (2021). Alertas alimentarias de interés general. Web: https://www.aesan.gob.es/AECOSAN/web/seguridad alimentaria/subseccion/otras ale rtas alimentarias.htm\#

Promotora dels Aliments CATAlans, PRODECA (2021). El sector agroalimentari és un dels principals sectors econòmics de Catalunya. Web: https://www.prodeca.cat/ca/sectors/el-sector-de-la-catalunya-agroalimentaria

Universitat de Barcelona, Facultat de Farmàcia i Ciències de l’Alimentació (abril 2021). Màster de Seguretat Alimentària. https://www.ub.edu/portal/web/farmacia-es/masteres-universitarios/-/ensenyament/de tallEnsenvament/551851

Universidad Complutense de MADRID (2021). Alimentación y medios de comunicación social.

Web: https://www.ucm.es/nutricion-humana/alimentacion-y-medios-de-comunicacion-social

Universitat Oberta de Catalunya (2021). Especialización de Educación y Comunicación Alimentaria.

Web:

https://estudios.uoc.edu/es/masters-posgrados-especializaciones/especializacion/cienci as-salud/comunicacion-educacion-alimentaria/programa-academico 